\title{
A FAMILY SET METHOD FOR ESTIMATING HEREDITY AND STRESS-II
}

\author{
PRELIMINARY RESULTS OF THE GENETIC METHODOLOGY IN A \\ PILOT SURVEY OF NEGRO BLOOD PRESSURE, DETROIT, 1966-1967
}

\author{
William J. Schull, ${ }^{*}$ Ph.D., Ernest Harburg, $\dagger$ Ph.D., John C. Erfurt $\ddagger$ M. \\ ANTHONY SCHORK, $§$ Ph.D. and RICHARD RICE $\uparrow$
}

(Received 23 April 1969; in revised form 3 November 1969)

THE PURPOSES of this report are to describe a method to evaluate genetic components of variability using survey techniques, and to present preliminary results from the application of this method to crude measures of skin color and height, and to blood pressure. Most recent evidence suggests that the genetic contribution to the observed variability between individuals in blood pressure, systolic and diastolic, is multifactorial in nature, and that hypertension is merely "one tail" of a continuous distribution [1,2]. While this point of view does not as yet have universal acceptance, meaningful estimates of the genetic contribution must ultimately relate differences in blood pressure to quantifiable genotypic differences irrespective of the number of genes involved or the nature of their action. Fortunately, genetic theory specifies the proportion of independently segregating autosomal genes which various biological relatives will share on the average. Thus, parent and offspring or siblings will share half of their genes in common; first cousins, one-eighth, and so forth. These proportions may also be interpreted as the probability for any given (autosomal) gene specified in one person that the stated relative will possess the same gene, in the sense of a gene of common origin. These proportions are termed coefficients of relationship, and are clearly measures of genetic similarity. Commonness of origin implies that both genes have been derived from a single ancestral gene.

The complements of the aforementioned coefficients may be regarded as measures of genetic dissimilarity or distance from commonness of origin. In this latter view, the average percentage of genes of dissimilar origin between (1) an index case and himself (or herself) is zero, (2) index and his (her) sibling is 50 per cent, (3) index and his (her) first cousin is 87 per cent, (4) index and his (her) spouse is 100 per cent, assuming no biological relationship, and, finally (5) index and his (her) control is

\footnotetext{
*Professor of Human Genetics, Medical School and Professor of Anthropology, College of Literatu re Science and the Arts, The University of Michigan.

†Research Associate, Department of Psychology, The University of Michigan.

$\ddagger$ Department of Psychology, The University of Michigan.

$\S$ Associate Professor of Biostatistics, School of Public Health, The University of Michigan.

ףResearch Assistant, Department of Psychology, The University of Michigan.
} 
100 per cent. This genetic scale, it will be noted, ranges from 0 to 100 per cent, and, to reiterate, represents the expected proportion of independent autosomal genes of dissimilar origin. The genetic analyses set out in this article attempts to relate these differences in distance between an index case and other members of his (her) family set to differences in blood pressure with due allowance for other sources of variability, primarily socio-environmental.

A prior article [3] has outlined the broader effort to evaluate the socio-environmental and genetic contributions to variability in systolic and diastolic blood pressure. Briefly, this involved an analysis of socio-environmental, genetic, and blood pressure variability within "family sets." Each family set consisted of 5 persons, namely, a randomly selected individual, the "index case," his or her full siblings, first cousin, spouse, and an individual of the same sex, referred to as the "unrelated person." The index cases for the pilot analysis were Negro males and females between the ages of 30 and 54, married and living with their spouses. Each had to have a full sibling and a cousin within five years of his or her age residing somewhere in the Detroit Metropolitan Area. The index cases were randomly selected from 2 predominantly Negro census tracts which differed greatly on such ecological dimensions as socioeconomic level, residential and marital stability, density, and crime rate. The unrelated cases were individually matched with the index cases in respect to race, age (within 5 years), marital status, residence in the census tract, and presence of a full sibling and first cousin within the Detroit Metropolitan Area, who were also within $5 \mathrm{yr}$ of age of the unrelated person.

Obviously, the procedure described thus far could be applied to a variety of combinations of relatives. The specific ones here used were chosen because they shared quite disparate proportions of genes in common, could presumably be ascertained with little or no ambiguity, and as contemporaries, only slight temporal variability would be expected to be confounded with the within-set variability.

\section{METHOD}

The appropriateness of this genetic distance scale as a means to estimate the heritablecomponent in blood pressure can be tested by the behavior of the scale insofar as other variables considered to have a relatively high heritability, such as height and skin color, are concerned. Such "marker" variables will be measured more precisely in a future clinical study. In the pilot survey, from which the observations to be reported are drawn, as a matter of convenience to an overburdened staff, height was verbally reported in inches by the respondent and skin color was rated on a four-point scale by the nurse-interviewers. The four points were (1) "very light," (2) "somewhat light (tan)," (3) "somewhat dark (brown)" and (4) "very dark brown or black." Both of these variables were more or less symmetrically distributed about their means.

Preliminary to analysis, the observed heights and skin colors were converted into "index-based, $d$-scores." For example, within each family set, differences in height between the index case and his (her) sibling, cousin, spouse, and unrelated person were computed. The height scores were first sex-adjusted by taking the residuals or discrepancies of observed and predicted scores using regression analysis. To the extent that these height differences reflect differences in genetic constitutions, the absolute difference in height between the index case and siblings should be smaller, on 
the average, than the absolute difference between index case and cousin which, in turn, will be smaller than the absolute differences between index and spouse (in the absence of assortative mating) or index and unrelated person. This follows from the fact that the genetic contribution to the variance of the difference between individuals will increase as genetic relationship decreases, and the mean deviation, that is the mean of the absolute differences, is a measure of dispersal.

Thus, if genetic variation is an important contributor to the observed variability in height, one expects, at the least, that a rank ordering of differences in height (or $d$-scores) among pairs of family set members will match the rank order of the genetic distances among the same pairs. More importantly, assuming gene action is additive (or nearly so), if differences in height between family set pairs were regressed on genetic distances within each set for all possible sets, than the variance in the distribution of all such regression coefficients should be significantly greater than the mean residual within-set variability; this would not be expected to obtain if the genetic contribution was zero or approximately so. It should be noted, however, that the average of all within-set regression coefficients could be zero even if all of the observed variability were of genetic origin, depending on the shape of the distribution, e.g. bimodal or trimodal.

It was necessary, for a complete analysis, therefore to compute difference scores on " $d$-scores" for all of those variables whose relationship to genetic distance was investigated, that is, for seven variables-height, skin color, observed and adjusted systolic blood pressure, observed and adjusted diastolic blood pressure, and "hypertension." The last variable is simply a score of 1 or $0-1$, if either the systolic pressure equalled or exceeded $160 \mathrm{~mm}$ of mercury or the diastolic pressure exceeded $95 \mathrm{~mm}$ of mercury, and 0 otherwise. It should be noted that while we use expressions "hypertensive" and "hypertension" as just defined, they are not intended to identify disease categories. Only 2 physiological measures, blood pressure and pulse rate, were measured and further information is patently desirable if disease states are to be identified. The coefficients of variation associated with these $d$-scores were all approximately one when the differences are measured in absolute terms, but vary from about 6 in in the case of one measure of systolic blood pressure to almost 60 in the case of skin color when signed differences are used. These values clearly suggest that significant findings, in the statistical sense, are improbable with the small number of observations at our disposal in this pilot survey even for the strongly inherited variables, e.g. skin color.

\section{Blood pressure}

The procedures used to measure blood pressure in the home in this study have been referenced in the earlier article [3]. It must be emphasized that the findings to be presented here are preliminary and are offered only for the insight which they afford into the study design. The number of individuals available in the various contrast groups are too few as yet for the estimates to have the desired precision although, of course, they are presumably still unbiased. Otherwise stated, tests of significance in the present instance have little power in the statistical sense, but one remains free to interpret the various estimates at their face value with due caution.

Among the 280 members of the 56 family sets in this pilot study, there was a slight tendency for blood pressure levels to increase in the course of the $1 \frac{1}{2} \mathrm{hr}$ interview. 
For the males in the sample, this increase amounted to $5 \mathrm{~mm}$, on the average, in the systolic pressures (125-130) and $2 \mathrm{~mm}$ in the diastolic pressures (87-89); for the females, the average rises in systolic and diastolic pressures were $6 \mathrm{~mm}(120-126)$ and $1 \mathrm{~mm}(84-85)$ respectively. These findings are pertinent since experience has shown that blood pressure readings in a clinic setting are more likely to decrease with time. If not fortuitous, these changes attest anew to the hazards in extrapolating from a clinical to a non-clinical environment, and contrariwise; they also have implications for analysis, and particularly call attention to the omnipresent possibility of confounded extraneous variability.

The 5 systolic readings as well as the 5 diastolic pressures were strongly intercorrelated, the range of the correlations for the former being 0.84-0.97 and for the latter, 0.85-0.93. As a consequence, the first three readings (taken at the beginning of the interview) were combined into an "initial mean systolic" and an "initial mean diastolic" pressure. The fourth and fifth readings (taken at the end of the interview) were likewise combined into mean levels, the so-called "final mean pressures." These mean pressures, initial and final, were also strongly correlated, and we shall, therefore, report here only the observations with respect to the initial mean readings.

As expected, age and weight were found to be moderately, but significantly corrclated with blood pressure. Again, for convenience in the field, weight was measured solely by the reports of each respondent to these two questions: "How much do you weigh now?" and "What is the most you have ever weighed in your life?" (not counting pregnancy for females). The correlation of present weight and "most ever weighed" was high, 0.94, but "most ever weighed" was consistently more highly correlated with blood pressure than present weight. For this reason, "most weighed" rather than present weight has been used in the analysis. The correlations of age and "most weighed" with mean blood pressure levels are as follows:

\begin{tabular}{|c|c|c|c|c|c|}
\hline & \multirow[b]{2}{*}{$N$} & \multicolumn{2}{|c|}{ Initial mean } & \multicolumn{2}{|c|}{ Final mean } \\
\hline & & Systolic & Diastolic & Systolic & Diastolic \\
\hline Age & $(280)$ & 0.28 & 0.24 & 0.30 & 0.33 \\
\hline Most weighed & (280) & 0.37 & 0.34 & 0.33 & 0.32 \\
\hline
\end{tabular}

Together, age and "most weighed" account for 17 per cent of the variation in mean systolic levels and about 12 per cent of the variation in mean diastolic levels as determined by multiple regression analysis. Tables 1 and 2 reveal the extent of the increase in blood pressure with age, and "most weighed" in these data.

Prior to genetic analysis of these observations, the mean blood-pressure levels were adjusted for sex, age, and most weighed by using stepwise multiple regression analysis. The residuals, or discrepancies between observed and predicted scores obtained by this technique are referred to as "mean adjusted systolic" and "mean adjusted diastolic" pressure. The unadjusted mean blood pressure levels are designated as "mean observed systolic" and "mean observed diastolic" pressures. Indexbased, $d$-scores were computed for both the observed and the adjusted pressures and separately analyzed.

\section{Genetic analysis}

Three different types of statistical techniques or approaches have been used in the 
Table 1. Group aVerages of mean bloOd pRessure leVels and percentage of hypertensive

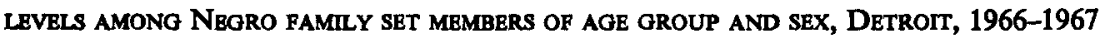

\begin{tabular}{|c|c|c|c|c|c|c|c|c|}
\hline \multirow[b]{2}{*}{ Age group } & \multicolumn{4}{|c|}{$\begin{array}{l}\text { Males }(N=134) \\
\text { First mean }\end{array}$} & \multicolumn{4}{|c|}{$\begin{array}{c}\text { Females }(N=146) \\
\text { First mean }\end{array}$} \\
\hline & $N$ & Syst. & Diast. & $\begin{array}{l}\% 160+ \\
\text { or } 95+\end{array}$ & $N$ & Syst. & Diast. & $\begin{array}{l}\% 160+ \\
\text { or } 95+\end{array}$ \\
\hline $\begin{array}{l}\text { Under } 25 \\
25-34 \\
35-44 \\
45-54 \\
55-59\end{array}$ & $\begin{array}{r}(0) \\
(27) \\
(53) \\
(45) \\
(9)\end{array}$ & $\begin{array}{l}\overline{124} \\
125 \\
139 \\
130\end{array}$ & $\begin{array}{l}\overline{83} \\
84 \\
92 \\
86\end{array}$ & $\begin{array}{l}\overrightarrow{19 \%} \\
17 \\
40 \\
22\end{array}$ & $\begin{array}{r}(3) \\
(42) \\
(71) \\
(26) \\
(4)\end{array}$ & $\begin{array}{l}111 \\
119 \\
127 \\
139 \\
135\end{array}$ & $\begin{array}{l}68 \\
81 \\
85 \\
87 \\
87\end{array}$ & $\begin{array}{l}\overline{19} \% \\
20 \\
23 \\
25\end{array}$ \\
\hline & (134) & 130 & 86 & $25 \%$ & (146) & 127 & 84 & $20 \%$ \\
\hline
\end{tabular}

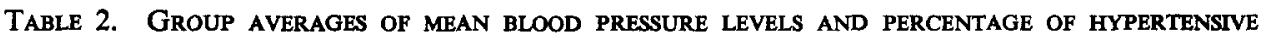
levels among Negro family set members by weigitt CATEgory and SEX, Detrort, 1966-1967

\begin{tabular}{|c|c|c|c|c|c|c|c|c|}
\hline \multirow[b]{2}{*}{$\begin{array}{l}\text { Most } \\
\text { weighed* }\end{array}$} & \multicolumn{4}{|c|}{$\begin{array}{l}\text { Males }(N=134) \\
\text { First mean }\end{array}$} & \multicolumn{4}{|c|}{$\begin{array}{l}\text { Females }(N=146) \\
\text { First mean }\end{array}$} \\
\hline & $N$ & Syst. & Diast. & $\begin{array}{l}\% 160+ \\
\text { or } 95+\end{array}$ & $N$ & Syst. & Diast. & $\begin{array}{l}\% 160+ \\
\text { or } 95+\end{array}$ \\
\hline $\begin{array}{l}\text { Below } 129 \\
130-149 \\
150-169 \\
170-189 \\
190-209 \\
210+\end{array}$ & $\begin{array}{r}(9) \\
(28) \\
(41) \\
(33) \\
(23)\end{array}$ & $\begin{array}{l}126 \\
128 \\
125 \\
131 \\
141\end{array}$ & $\begin{array}{l}81 \\
83 \\
85 \\
89 \\
92\end{array}$ & $\begin{array}{l}11 \\
21 \\
19 \\
30 \\
39\end{array}$ & $\begin{array}{l}(23) \\
(32) \\
(31) \\
(27) \\
(15) \\
(18)\end{array}$ & $\begin{array}{l}119 \\
119 \\
120 \\
129 \\
130 \\
153\end{array}$ & $\begin{array}{r}79 \\
81 \\
83 \\
84 \\
84 \\
100\end{array}$ & $\begin{array}{l}13 \% \\
16 \\
16 \\
15 \\
13 \\
56\end{array}$ \\
\hline & (134) & 130 & 86 & $25 \%$ & (146) & 127 & 84 & $20 \%$ \\
\hline
\end{tabular}

*These weight categories are based on responses to the questionnaire item, "What is the most you cver weighed in your life?" (not counting pregnancy for females).

exploration of these data. The first was simply to compare correlations between family set pairs for the seven variables, i.e. skin color, height (adjusted for sex), mean observed systolic and diastolic blood pressure, mean adjusted systolic and diastolic pressure (adjusted for sex, age, and most weighed) and hypertension. The second analysis involves simple regressions within each family set of each of the seven previously enumerated variables, expressed as $d$-scores, on genetic distance. This provides a descriptive picture of the regression coefficients for each of the 56 family sets. The third and final approach consisted of simple regressions of each major variable on genetic distance from all 56 family sets combined.

\section{FINDINGS}

Table 3 presents the results of separate, paired correlations between the index cases and the other family set members for skin color, height, observed and adjusted blood pressure levels, and hypertension. On genetic grounds, the correlations between the index cases and their siblings should be higher than those between index cases and cousins; theoretically, if gene action is simple and additive, these correlations should be 0.50 and 0.125 , respectively. The correlations between the index cases 
TABLE 3. CORRELATIONS OF SKIN COLOR, HEIGHT, AND BLOOD PRESSURE LEVELS BETWEBN INDEX CASES AND OTHER FAMLY SET MEMBERS BY RANK ORDER OF GENETIC RELATIONSHIP

\begin{tabular}{|c|c|c|c|c|c|c|c|c|}
\hline \multirow{2}{*}{$\begin{array}{l}\text { Rank order } \\
\text { of genetic } \\
\text { correlation } \\
\text { from high to low }\end{array}$} & \multirow[b]{2}{*}{$\begin{array}{l}\text { No. of } \\
\text { pairs }\end{array}$} & \multirow[b]{2}{*}{$\begin{array}{l}\text { Skin } \\
\text { color }\end{array}$} & \multirow[b]{2}{*}{ Height* } & \multicolumn{5}{|c|}{ Initial mean blood pressure readings } \\
\hline & & & & $\begin{array}{l}\text { Observed } \\
\text { systolic }\end{array}$ & $\begin{array}{l}\text { Observed } \\
\text { diastolic }\end{array}$ & $\begin{array}{l}\text { Adjusted } \\
\text { systolic } \dagger\end{array}$ & $\begin{array}{c}\text { Adjusted } \\
\text { diastolic } †\end{array}$ & $\begin{array}{l}\text { Hyper- } \\
\text { tensive }\end{array}$ \\
\hline 1. Index-sib & 56 & & & & 0.1 & -0.02 & 0.1 & 0.1 \\
\hline 2. Index $-c$ & 56 & o. & & & & & & \\
\hline Index-spouse & 56 & 0.12 & 0.12 & 0.06 & 0.17 & -0.09 & 0.2 & 0.30 \\
\hline 3. Index-control & 56 & 0.02 & 0.38 & 0.06 & 0.07 & -0.01 & 0.09 & 0.12 \\
\hline
\end{tabular}

*This variable was adjusted for sex.

†These variables were adjusted for sex, age, and most weighed.

and their cousins, on the other hand, should be higher than those between index cases and their spouses or matched unrelated persons. Again, if gene action is simple and additive, and mating is at random, these correlations should be $0.125,0$, and 0 , respectively. As is apparent from Table 3, these expectations are not realized. Although the rank order of correlations in skin color is in accord with theory, the specific values are not, if taken at face value. For height, even the order is at variance; the correlation between the index case and his unrelated person is markedly discrepant. No explanation for this other than fortuity suggests itself. A bias in the selection procedure seems improbable; the correlations between the index case and the unrelated person for skin color, or, as we shall see, for blood pressure, differs trivially from zero. The positive correlations between index case and spouse for skin color and height, though not significant, are however probably real and reflect assortative mating with respect to these traits. Finally, for blood pressure and hypertension, neither the order nor the magnitude of the correlation coefficients accord with theory; in fact, few of these correlations can even be shown to be significantly different from zero. It should also be pointed out, however, that insofar as height and skin color are concerned the observed correlations are not significantly different from the simple expectations previously described.

The results of an alternative approach to these data are set out in Table 4. This table gives the mean absolute $d$-scores of these variables for siblings, cousins, spouses, and unrelated persons. The variance of the differences in $d$-scores should diminish as biological relationship between the index case and the individual with whom he or she is compared increases (although the signed mean difference may converge on zero).

To the extent, however, that the absolute difference reflects the dispersal of the observations, the mean absolute $d$-scores, averaged over family sets, should fall into one or the other of the two following rank-order patterns on theoretical grounds:

$$
\begin{aligned}
& \text { Spouses }>\text { Unrelated }>\text { Cousins }>\text { Siblings } \\
& \text { or } \\
& \text { Unrelateds }>\text { Spouses }>\text { Cousins }>\text { Siblings }
\end{aligned}
$$

The uncertainty associated with spouses and unrelated persons reflects the possibility of (1) some confounding of sex differences in the comparison of the index case with his or her spouse which would not occur in the comparison of the index case with the unrelated person who has been matched on sex, and (2) a minimization of the 


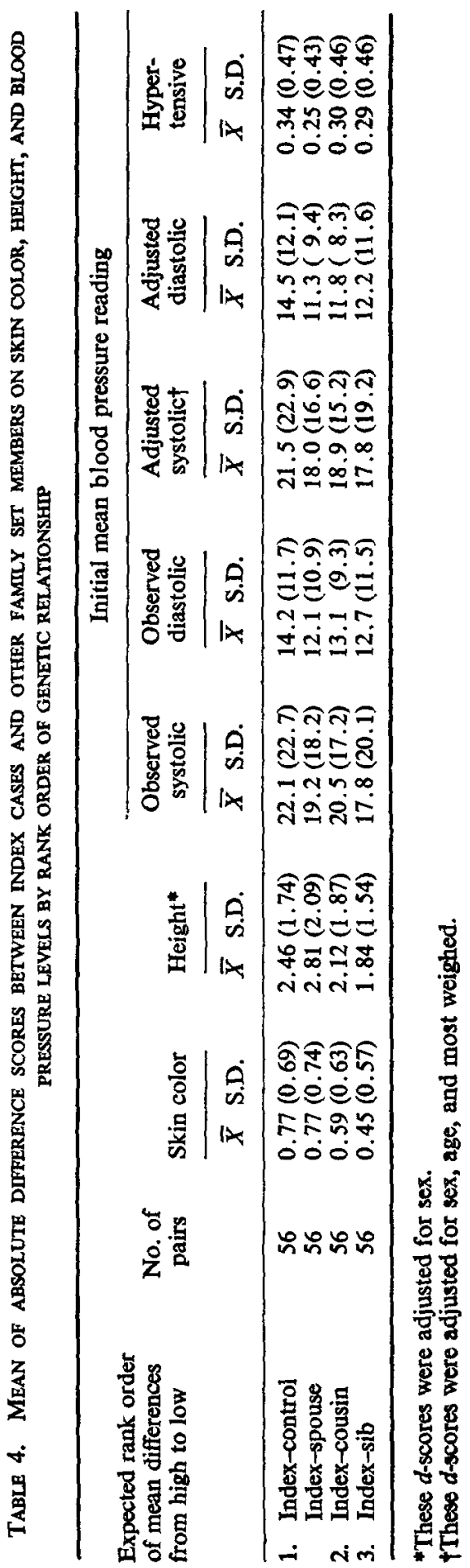



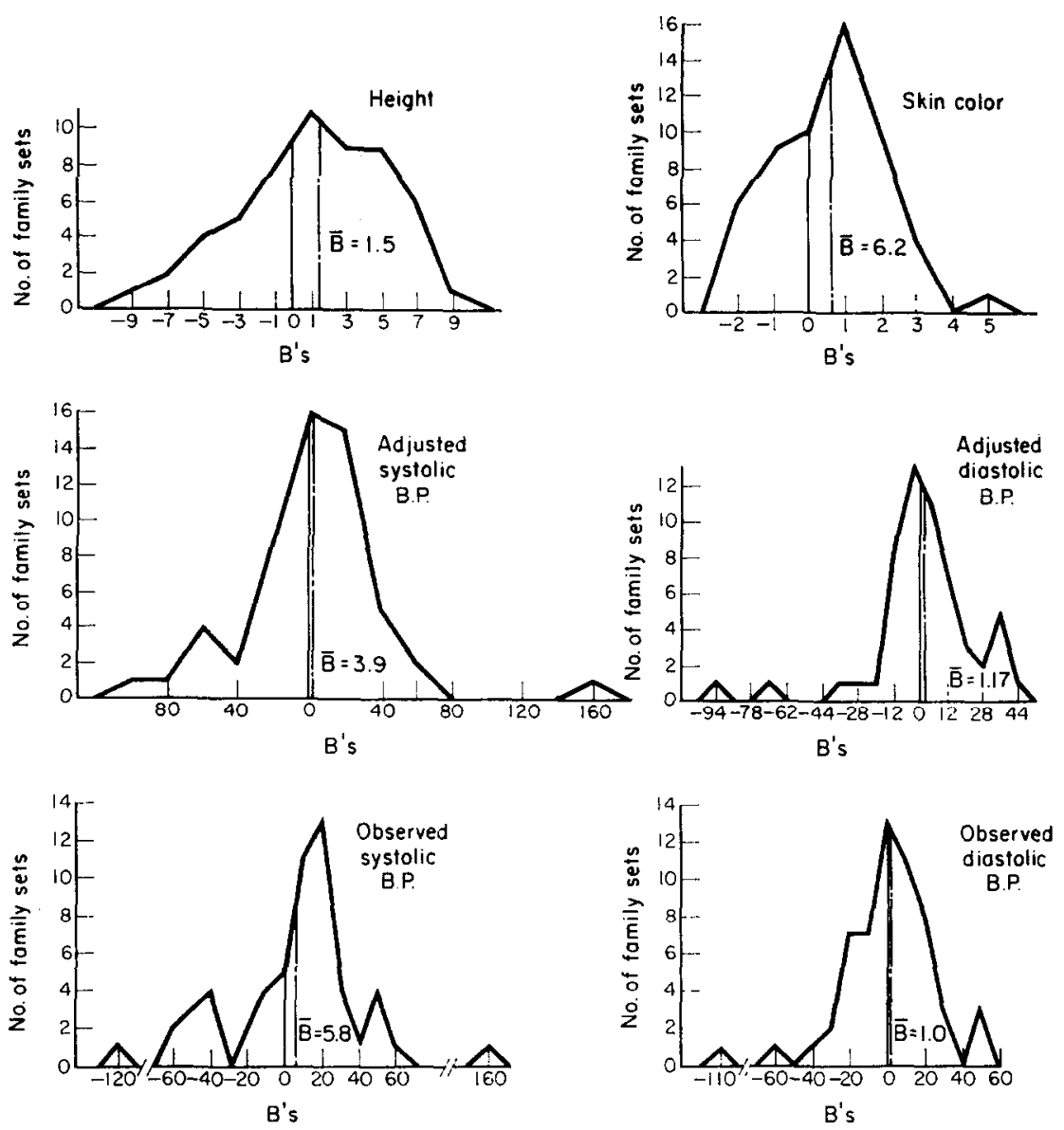

Fig. 1. Each polygon shows the distribution of B's resulting from 56 within-familyset regressions of the genetic distance scale onto $d$-scores for the given variable. $N=56$ B's per polygon.

environmental effect through the correlation in "life styles" which accompanies marriage. The former would tend to make the absolute $d$-scores greater for spouses than unrelated, and the latter would reverse this order. Given this qualification, the rank-order patterns of the mean absolute $d$-scores for skin color and height are as expected, or nearly so, but again, the orders for blood pressure and hypertension are discrepant.

Fig. 1 discloses the results of six sets of distributions of regression coefficients. Regression analysis was first computed within each family set for $d$-scores or differences in height, skin color, observed and adjusted blood pressure, systolic and diastolic, on genetic distance. A picture of the resulting distribution of 56 raw score regression coefficients for each of the 6 dependent variables is provided in the form of a frequency polygon. The mean regression coefficient of these simple regressions across all 56 family sets is also provided. Inspection of this figure reveals that the array of regression coefficients for each variable tends to be normally distributed, or more properly, symmetrically distributed around the mean coefficient, Moreover, 
TABLE 5. SEVEN REgRESSIONS OF GENETIC DISTANCE SCALE ON DIFFERENCES (d) SCORES FOR SKIN COLOR, HEIGHT, AND BLOOD PRESSURE LEVELS FOR ALL 56 FAMILY SETS COMBINED

Independent variable: Genetic distance scale

\begin{tabular}{lccccc}
\hline Dependent variable & $\begin{array}{c}\text { No. of } \\
\text { data cases* }\end{array}$ & Beta $\dagger$ & B $\ddagger$ & $t$-ratio $\S$ & $p$ \\
\hline 1. $d$-skin color & 224 & 0.19 & 0.62 & 2.92 & 0.01 \\
2. $d$-height $\Phi$ & 224 & 0.17 & 1.50 & 2.59 & 0.01 \\
3. $d$-initial $\bar{X}$ observed systolic & 224 & 0.06 & 5.77 & 0.90 & N.S. \\
4. $d$-initial $\bar{X}$ observed diastolic & 224 & 0.02 & 0.93 & 0.26 & N.S. \\
5. $d$-initial $\bar{X}$ adjusted systolic** & 224 & 0.04 & 3.90 & 0.64 & N.S. \\
6. $d$-initial $\bar{X}$ adjusted diastolic** & 224 & 0.02 & 1.17 & 0.34 & N.S. \\
7. $d$-initial $\bar{X}$ hypertensive & 224 & 0.01 & 0.02 & 0.13 & N.S. \\
\hline
\end{tabular}

"In each of these regressions, the index case, having a genetic distance score of " 0 ", is omitted. †Beta is the correlation between the genetic distance scale and the dependent variable.

$\ddagger$ This is the average "within-set" regression coefficient.

§These ratios are based upon the assumption that no significant heterogeneity exists between family set regression coefficients. The small number of observations presently available preclude meaningful examination of the validity of this assumption.

IThese $d$-scores were adjusted for sex.

**These $d$-scores were adjusted for sex, age, and most weighed.

the array tends to shift with internal consistency from zero to the right, or towards the "positive" end of the scale. This shift is statistically significant, however, only for height and skin color; otherwise stated, only for height and skin color does the mean regression coefficient differ significantly from zero. It should be noted that the scale ranges of the $d$-score variables for height and skin color, 0-8.4 and 0-3, respectively, are small when compared with similar ranges for systolic and diastolic blood pressure (0-120 and 0-65.4 for observed systolic and diastolic pressure, and 0.1-122.7 and $0.1-66.8$ for the adjusted pressures).

While the mean regression coefficients for the observed and adjusted systolic and diastolic pressures did not reach significance when tested against zero, the distributions of these coefficients are skewed in the same direction as height and skin color namely, to the positive end of the scale, Failure here to achieve significance could well be due to the small sample size, and the greater variability of the metrics of blood pressure. With a small sample of family sets, the principal function of this type of statistical approach is, perhaps, to provide some evidence with respect to the internal consistency of the data.

Table 5 exposes the results of seven separate regression analyses of the genetic distance scale onto the $d$-scores for the various dependent variables. These findings indicate that the regressions of the genetic distance scale to height and to skin color are significant at the 0.01 level, while only a negligible statistical relationship is found with each of the 5 blood pressure variables.

The findings from the above complex of analyses tend to support the validity of the genetic distance scale when tested against variables with an established genetic basis such as height and skin color even when these marker variables were crudely measured. These data, furthermore, provide us with a degree of confidence that the respondents in the pilot study constitute a bona fide "family set" sample. These preliminary 
findings do not, however, show evidence of strong associations between genetic distance and differences in blood pressure and hypertensive levels.

\section{SUMMARY}

A prior article described in detail a pilot survey designed to measure the effects of heredity and stress on blood pressures among Negroes residing in high and low stress census tracts in Detroit. This report outlines the construction of a genetic variable to analyze the heritable component in blood pressure variability using a family set composed of an index and spouse, a sibling and a first cousin of index, and an unrelated person in the tract matched to index. Given the theoretical proportions describing the degree to which genes are shared between siblings and first cousins, then it follows that variability of a given trait will increase predictably within each family set. Findings from a limited sample of 56 family sets indicate support for a genetic distance scale when measured against variables such as height and skin color; however, the relationship with blood pressure levels is inconclusive. A study now underway will more critically test the tentative findings from this pilot survey.

\section{REFERENCES}

1. Acheson RM, Fowler GB: On the inheritance of stature and blood pressure $\mathbf{J}$ Chron Dis 20: 731-745, 1967

2. Miall WE, Heneage $P$, Khosla $T$, et al: Factors influencing the degree of resemblance in arterial pressure of close relatives. Clin Sei 33: 271-283, 1967

3. Harburg E,Schull WJ, Erfurt JC, et al: A family set method for estimating heredity and stress-I. A pilot survey of blood pressure among Negroes in high and low stress areas, Detroit, 19661967. J Chron Dis 23: 69-81, 1970 